\title{
MONOGRAFIAS DE FIM DE CURSO - REFLETINDO SOBRE NOSSAS REFLEXÕES: POR ONDE CAMINHAMOS?
}

\author{
Victor ANDRAde De Melo*
}

[...] a competência tecnológica advém da capacidade educativa de cada sociedade, desde que não se restrinja à fabricação de idiotas especializados (...). De si, a tecnologia é apenas capacidade de instrumentação. Cabe à educação unir os dois lados num todo só, garantindo para compromissos humanistas instrumentação efetiva. (PEDRO DEMO)

\section{RESUMO}

Este artigo tem por objetivo discutir a estrutura educacional relacionada com a exigência de um trabalho de conclusão de curso na Escola de Educação Física e Desportos da Universidade Federal do Rio de Janeiro (EEFD/UFRJ). O artigo está inserido no esforço de catalogação e publicação dos resumos das monografias apresentadas no curso de bacharelado de Educação Física da EEFD/UFRJ. Ao rever, recuperar, catalogar e analisar as monografias apresentadas, não se está exatamente interessado em discutir as direções teórico-metodológicas desses estudos. Pretende-se, neste artigo, abordar os problemas de concepção e de ordem operacional que existem ao redor da exigência de apresentação de uma monografia. Ao mapear tais problemas, buscamos, a partir do caso da EEFD/UFRJ, abrir uma linha de diálogo e contribuir com outros colegas e outras instituições que desejem pensar e repensar a importância das monografias, que, mais do que uma exigência cartorial, deveriam ser compreendidas como um retrato da forma com a qual a pesquisa é considerada no âmbito da formação profissional.

PALAVRAS-CHAVE: Pesquisa-Formação profissional-Monografia.

exigência de confecção de um trabalho monográfico para que
tido, uma novidade na formação profissional na Educação Física
brasileira. Basta lembrar que a Escola de Educação Física do Espí-
rito Santo, criada como Curso Normal em 1931, em suas origens
exigia de seus alunos a apresentação de um trabalho para que fosse
possível a aprovação final no curso. ${ }^{1}$

* Prof. adjunto do Departamento de Ginástica da Escola de Educação Física e Desportos da Universidade Federal do Rio de Janeiro. 
Apesar de ser interessante o exemplo anterior, podemos afirmar que foi mesmo na década de 1980 que as monografias passaram a ser uma crescente exigência nos cursos de graduação em Educação Física. Fundamentalmente, a partir da Resolução n. ${ }^{\circ} 3 /$ 87 do Conselho Federal de Educação, que reformulara a formação profissional na área. Entre outras providências, tornava-se obrigatória a apresentação de monografia nos recém-criados cursos de bacharelado em Educação Física.

É verdade que antes alguns cursos já adotavam a monografia como exigência - provavel influência do contexto peculiar da nossa área na década de 1980, no qual foi marcante a busca de um "padrão de cientificidade". Mas por certo a nova legislação, embora específica para o bacharelado no que se refere à monografia, influenciou muitos novos e antigos cursos de licenciatura a adotarem-na como requisito para a diplomação dos alunos. ${ }^{2}$

A Escola de Educação Física da Universidade Federal do Rio de Janeiro (EEFD/UFRJ), baseada em tal legislação, também criou seu curso de bacharelado em Educação Física no ano de 1994. A partir de então, a EEFD/UFRJ passou a conviver com dois cursos ligados à Educação Física - um de licenciatura (diurno) e outro de bacharelado (noturno) - além de um curso de bacharelado em dança (também noturno). ${ }^{3}$ Em todos é obrigatória a apresentação de uma monografia ao final do curso.

$\mathrm{Na}$ verdade, tal adoção partiu de uma análise anterior, de que faltava estímulo à produção científica na EEFD/UFRJ. Assim, em vários momentos da proposta de mudança curricular da licenciatura e de criação do bacharelado em Educação Física, indicava-se o incentivo à pesquisa como fundamental para um novo perfil de profissional de Educação Física. ${ }^{4}$

Sendo professor da disciplina ${ }^{5}$ Monografia nesta instituição desde 1999, comecei a me incomodar com a estrutura existente, relacionada com a exigência de um trabalho de conclusão. Foi esse incômodo que me levou a escrever o presente artigo, inserido no esforço de catalogação e publicação dos resumos das monografias apresentadas no curso de bacharelado de Educação Física da EEFD/ UFRJ desde o segundo semestre de 1998 (primeiras monografias apresentadas) até o segundo semestre de $2000{ }^{6}$ 
Ao rever, recuperar, catalogar e analisar as monografias apresentadas, não estou exatamente interessado em discutir as direções teórico-metodológicas desses trabalhos. Muitas pesquisas foram feitas nesse sentido e com certeza têm seu valor. O que pretendo abordar são os problemas de concepção e de ordem operacional que existem ao redor da exigência de apresentação de uma monografia. Ao mapear tais problemas, a pretensão básica deste artigo é abrir uma linha de diálogo e contribuir com outros colegas e outras instituições que desejem pensar e repensar a importância das monografias, que, mais do que uma exigência cartorial, deveriam ser compreendidas como um retrato da forma com a qual a pesquisa é considerada no âmbito da formação profissional.

\section{UM PANORAMA}

Na EEFD/UFRJ, aos alunos são oferecidas três disciplinas diretamente relacionadas com a pesquisa: Introdução à Metodologia Científica ( $1^{\circ}$ período); Metodologia da Pesquisa ( $4^{\circ}$ período) e Requisito Curricular Suplementar (RCS) Monografia (no $7^{\circ}$ e $8^{\circ}$ períodos). Depois de cursar as duas primeiras disciplinas, o aluno se inscreve no RCS e tem dois períodos para concluir sua monografia, contando com a orientação de um professor, em uma relação oficialmente estabelecida. Como peculiaridade da Escola, podem ser formados grupos de até três alunos para cada monografia, em virtude do pequeno número de professores, se comparado com o grande contingente de estudantes. ${ }^{7}$

Podemos começar a refletir sobre os problemas a partir dessa estrutura disciplinar. A priori e por princípio, não há como negar a importância da exigência de uma monografia, se ela significar que optou-se por uma concepção de formação profissional no qual a pesquisa seja elemento central e indissociável do ensino.

Algumas perguntas merecem ser formuladas. Isso seria uma realidade na EEFD/UFRJ? Será que a maioria de nossos professores orienta suas disciplinas para estimular a leitura, o debate, a curiosidade, enfim, a pesquisa, ou ainda se atém ao velho modelo ensino-aprendizagem? Será que nossos professores estão sintonizados com as novidades, no que se refere às suas disciplinas, acessam 
com freqüência periódicos e livros atualizados e apresentam para os alunos uma bibliografia constantemente renovada, que indica conteúdos para além do que se pretende discutir em sala de aula?

Se as respostas forem positivas, temos então uma formação profissional que tende a apontar para a pesquisa. Se não, creio que estamos jogando em três disciplinas uma responsabilidade que deveria ser um princípio curricular, a tal ponto que pergunto provocativamente: vale a pena manter a exigência de uma monografia, se essa não estiver ligada a um contexto e compreensão de formação profissional? Não estaríamos, na verdade, forjando uma fraude: fingindo que estamos preocupados com a pesquisa somente por exigirmos uma monografia de nossos alunos? Pedro Demo nos apresenta uma reflexão bastante contundente e inquietante:

Na própria concepção moderna de ciência, cujo centro é o desafio inovador incessante, emerge a motivação do questionamento permanente, que rejeita o mero repasse subalterno. Copiar não é ciência, ensinar a copiar não é educação. ${ }^{8}$

Nesse mesmo sentido, cabe também perguntar: se os alunos devem contar com um orientador para desenvolver suas pesquisas, estariam nossos professores preparados para assumir tal função, na medida em que se espera que também sejam pesquisadores? Se não foram preparados para isso, teriam eles procurado desenvolver tais habilidades desde a implantação da exigência de monografias? Ainda mais, estariam nossos professores realizando e dando continuidade às suas pesquisas, apresentado seus resultados em eventos e periódicos científicos e estimulando os alunos para tal?

Essa última pergunta é fundamental por estar relacionada com outra: quantos grupos de pesquisa organizados existem no âmbito da EEFD/UFRJ? Tais grupos são de grande importância, pois podem permitir engajar e incentivar precocemente os alunos no exercício da pesquisa, de forma organizada e sistemática. Sem falar que isso permite outros ganhos: para a sociedade, pois espera-se que as pesquisas realizadas nesses grupos tenham condições maiores de inserção social, já que não são esforços isolados; e para os próprios alunos, pois a organização em grupos é cada vez mais exigida para a conces- 
são de financiamentos e bolsas, importantes para possibilitar aos alunos um envolvimento ainda maior com a atividade de pesquisa.

Em um contexto de "fragilidade" no que se refere à pesquisa, não é surpreendente, por exemplo, que a maioria das monografias confeccionadas pelos alunos do curso de bacharelado em Educação Física da EEFD/UFRJ nunca tenha sido apresentada em eventos científicos e/ou publicada. Produzidas para atender a uma obrigação cartorial, desconectadas de grupos, longe de estímulos efetivos de construção de conhecimento, somente os alunos mais interessados - ou os que têm a "sorte" de contarem com professores que os encaminhem para o "mundo acadêmico" - acabam tendo a oportunidade de expor seu trabalho, sua produção, e debater seus avanços e deficiências. Uma vez mais, as palavras de Pedro Demo nos alertam: “(...) o problema essencial está na postura reprodutiva das universidades, reduzidas a entidades de mero ensino, sob a quimera de que conhecimento se restringe à transmissão". ${ }^{9}$

Enfim, dois dados significativos devem ser considerados em nossa realidade na EEFD/UFRJ. O primeiro é a existência de um número bem pequeno de grupos de pesquisa organizados. Lamentavelmente dispomos de poucos estímulos nesse sentido e de um número bem pequeno de bolsas de iniciação científica. ${ }^{10}$

O segundo dado é que, como professor de Monografia, pude identificar dificuldades de alguns alunos para encontrar orientadores. Isso pode ocorrer por vários motivos. Em alguns casos, de forma justificada, quando, por exemplo, os professores contactados já possuem um número elevado de orientandos. Vale lembrar que tal problema seria minimizado se houvesse grupos de pesquisa organizados, o que facilitaria o trabalho de orientação.

Em alguns casos, os alunos têm dificuldade de encontrar um orientador devido à natureza de sua temática. Isso, em certo sentido, justifica a dificuldade, já que não é simples promover reorientações no assunto que cada professor vem estudando. De outro lado, poderia servir como estímulo para que os professores se atualizassem e buscassem novas reflexões. Mas para tal, os professores deveriam assumir esse desafio.

Por fim, existem os casos não justificados: professores que se omitem ou se negam a orientar, por acreditarem que não é essa sua 
função ou argumentarem que não possuem competência para tal. Quanto a isso, é preferível nem comentar. Parece-me absurdo que um professor universitário utilize argumentos dessa natureza.

\section{AVALIANDO A AVALIAÇÃO}

Nesse contexto, onde a monografia não está inserida em um âmbito de estímulo amplo, central e contínuo de incentivo à pesquisa, sendo em muitos casos uma medida meramente cartorial, para atender a uma exigência burocrática, como lidar com a avaliação dos trabalhos produzidos?

$\mathrm{Na}$ verdade, devemos perceber que os alunos se encontram distribuídos em diversos grupos. Existem aqueles que desejam fazer uma boa monografia e de alguma forma encontram condições mínimas que lhes permitem desempenhar um bom papel. Existem também aqueles que desejam fazer um bom trabalho, não encontram condições adequadas, mas se superam com muito esforço e realizam uma pesquisa de qualidade. Entre esses, podemos encontrar também dois grupos: os que pretendem apenas fazer um bom trabalho de fim de curso e os que desejam seguir uma carreira acadêmica.

Há aqueles que encaram a monografia como um empecilho e somente fazem o mínimo necessário para serem aprovados. Entre esses, creio que existem muitos que poderiam ter uma posição diferenciada se fossem devidamente estimulados no decorrer do curso. Com certeza, também existem aqueles que, de qualquer forma, não desenvolveriam um trabalho de qualidade. Esses alunos devem ser respeitados: é um direito do aluno valorizar no decorrer do curso o que considera mais adequado e importante para o seu perfil profissional.

A questão não é jogar a responsabilidade exclusivamente para o aluno, mas perceber que a instituição é que tem de assumir o desafio de proporcionar estímulos adequados e condições concretas para uma formação de qualidade. Volto a afirmar que, de maneira como a situação se apresenta, a monografia tem sua validade bastante reduzida.

Por exemplo, alguns afirmam que o desenvolvimento de uma monografia é uma experiência importante para estimular nos alunos o hábito de "consumir" pesquisas, mesmo que não optem por 
ser pesquisadores. Mas será que o fato de serem obrigados a confeccionar uma monografia, completamente desconectada do contexto de sua formação, será suficiente para os estimular ao "consumo" de produção científica atualizada? Creio sinceramente que não.

Voltemos à questão inicial: como avaliar o trabalho nesse contexto bastante complicado? Sugiro que devemos partir da consideração de que a pesquisa tem uma dupla face educativa: deve ser uma produção criativa e questionar a realidade. Baseado nessa dimensão e em algumas considerações de Pedro Demo, ${ }^{11}$ gostaria de apresentar algumas sugestões para avaliarmos as monografias, ato que também deve ser compreendido como forma de feed-back para os alunos, para que eles aprofundem o aprendizado a partir de alguns possíveis problemas encontrados. A avaliação poderia estar ligada a algumas perguntas básicas:

* A monografia apresenta uma forma produtiva de conhecimento? Demonstra a capacidade de interpretação crítica dos autores? Faz uso crítico de conhecimento disponível?

* A monografia apresenta uma síntese própria, um ponto de vista pessoal?

* Os alunos apresentaram capacidade de autogerirem seu acesso ao conhecimento, independência intelectual?

* Os alunos dominam minimamente procedimentos formais de pesquisa, segundo padrão que acreditem ser o melhor?

Nesse desafio de avaliar, deveríamos tomar alguns cuidados. Um risco seria o de enrijecer a análise em excesso, beirando a sofisticação elitista e a obsessividade no que se refere à originalidade. ${ }^{12}$ Nesse aspecto, preocupa-me em especial a cobrança excessiva na observância de normas de formato, muitas vezes traçadas de forma absolutamente "esotérica". Os livros de metodologia da pesquisa são díspares, confusos, muitas vezes ultrapassados, desrespeitando até mesmo princípios básicos, como a necessidade de observar as normas bibliográficas da Associação Brasileira de Normas Técnicas. ${ }^{15}$

É lógico que os aspectos gráficos não são desprezíveis, mas minha experiência mostra que certos alunos ficam mais preocupados com a apresentação do que com o conteúdo em si. E alunos-profes- 
sores, às vezes, escondendo suas dificuldades de analisar com segurança o conteúdo, também incorrem nessa preocupação excessiva.

Outro risco seria o de banalizar a produção da monografia. Isto é, reconhecendo que há problemas, escrever qualquer coisa. Não podemos aceitar tal atitude. Com todos os limites e problemas, os orientadores devem se empenhar em obter o máximo de seus alunos. Obviamente devemos respeitar os níveis de conhecimento dos alunos e das instituições, mas tensionar sempre em busca de qualidade. Mais ainda, oferecer o máximo possível a cada aluno.

Essa preocupação com a qualidade fica ainda mais denotada em virtude de nosso curso de bacharelado ser realizado no período da noite. Além de estar sendo uma experiência bastante feliz e fértil lecionar em um curso noturno, quero me declarar entusiasta dessa opção, mesmo que, no caso da UFRJ, não concorde e não me sinta à vontade com o fato de ser um bacharelado. De qualquer forma, acredito fielmente que um cidadão, ainda que trabalhe durante o dia, deva ter acesso a curso de Educação Física em uma universidade pública. E a UFRJ é a única que cumpre esse papel no Estado do Rio de Janeiro.

Sabemos das dificuldades dos alunos, professores e instituições com os cursos noturnos, mas não podemos utilizá-las para justificar que sejam diferentes ou de "menor qualidade" que os cursos diurnos, que sejam de "segunda categoria". Temos que pleitear a mesma qualidade exigida para o curso diurno, inclusive no que se refere à pesquisa. Quanto a isso, Pedro Demo chama bem a atenção:

Será totalmente inútil, para não dizer cultivo do atraso, aceitar a carapuça de entidade de mero ensino, porque seria reservar para o pobre, instituição pobre, para que continue pobre. Cursos noturnos de mero ensino são stricto sensu restos para uma população mantida como resto, embora amplamente majoritária. ${ }^{14}$

Nossa experiência na UFRJ mostra alguns dos problemas acima levantados, com certas peculiaridades. Um ponto louvável é a existência de uma ficha-padrão de avaliação, com pontuação previamente estabelecida. Interessante também é o fato de que tal ficha não contempla somente a monografia em si (o "produto" fi- 
nal), mas também o processo de confecção, a ser avaliado pelo orientador e pela professor de Monografia. ${ }^{15}$

Se isso é uma vantagem, temos, no entanto, que apontar os limites da ficha de avaliação das monografias da EEFD/UFRJ. O instrumento se prende excessivamente a detalhes, sem estabelecer princípios e pontuando, equivocadamente, com excesso, o aspecto gráfico e mesmo limitando o formato de realização da pesquisa, predeterminado a partir de um padrão único. Logo, a ficha de avaliação acaba por avaliar muito pouco ou por não avaliar o essencial.

Mais ainda, minha experiência mostra que pouco é devolvido aos alunos em termos de retroalimentação. Isso somente mais uma vez configura o que tenho tentado argumentar no decorrer desse capítulo: não são poucos os casos em que a monografia transforma-se no simples atendimento a uma exigência burocrática.

\section{ALGUNS APONTAMENTOS}

Após a crítica acima, pode o leitor pensar que sou a favor da eliminação da exigência de apresentação de uma monografia nos cursos de Educação Física, o que não corresponderia de forma alguma a meu pensamento. Em realidade acredito que, mesmo em um quadro de completa precariedade, os trabalhos de fim de curso devem ser mantidos nos currículos. Isso se deve a um motivo simples e muito claro: apesar de todos os problemas, muitas vezes este é o único momento onde os alunos mais envolvidos acabam tendo seus interesses despertados.

Mais ainda, sou contrário à substituição da monografia por outros trabalhos, como a publicação de um artigo em uma revista científica. Ora, supõe-se que, se o aluno possui um artigo, ele foi extraído de uma pesquisa maior. Logo, o aluno deve apresentar ao curso esse esforço ampliado, segundo o formato sugerido.

De qualquer forma, devemos relativizar e ser sinceros quanto à função parcial na forma com a qual se apresenta hodiernamente a exigência das monografias. Isso não significa que devemos nos conformar com o quadro atual. Ao contrário, deveríamos assumir o desafio de reorientar a questão das monografias em si e utilizá-la como desafio central para repensar a dinâmica curricular, compreendida para além 
de sua grade. Isso pode ser bem interessante à nossa Escola, por exemplo, que passa por uma necessidade urgente de reformulação curricular.

A monografia deve ser compreendida como um "produto" conseqüente de uma compreensão da pesquisa como uma prática educativa. Mas jamais pode ser a única responsável por tal atitude. Deve haver um contexto de estímulo à pesquisa, que comece nas salas de aulas (com professores atualizados, pesquisadores e que estimulem constantemente seus alunos a uma postura crítica e de curiosidade permanente) e extravase para outros vários espaços, com a organização de grupos de pesquisa e estímulo constante à participação de alunos em eventos extracurriculares, entre os quais os científicos e os específicos do movimento estudantil.

Os alunos devem perceber que a formação não se encerra nas salas de aulas, nem tampouco no período universitário. Como bem afirma Pedro Demo: "Universidade é um lugar privilegiado da pesquisa, não um monte de salas de aula, onde alguns apenas ensinam e a maioria apenas aprende". ${ }^{16}$

A pesquisa pode e deve contribuir para que o aluno compreenda denotadamente a realidade que o cerca, nem sempre motivo de outros estudos científicos "mais amplos". Por exemplo, temos bastante estudos sobre a história da Educação Física e do Esporte no Brasil e nos grandes centros. Mas quantos estudos existem sobre os aspectos históricos desses objetos em outros locais, pequenas cidades ou regiões mais distantes? Poucos. O professor da disciplina História poderia então estimular no decorrer de seu curso a realização de trabalhos que procurem introdutoriamente resgatar essas dimensões nas cidades. Essa "pesquisa" inicial e introdutória, além de aproximar o aluno de sua realidade e do objeto estudado, pode ser o estímulo necessário para que ele aprofunde a temática como sua monografia, que depois pode mesmo vir a ser seus estudos de mestrado e doutorado. Mais ainda, essa pesquisa cumprirá uma função importante para a memória de sua cidade e de sua região. Já tivemos algumas experiências bastante interessantes seguindo esse exemplo.

A pesquisa, enfim, deveria ser princípio central dos cursos, não por uma valorização apriorística da ciência, mas por ela ocupar espaço de suprema importância no desafio educacional em termos de modernidade. ${ }^{17}$ 
Outra dimensão que me preocupa é que possamos garantir para nossos alunos o acesso à multiplicidade de possibilidades de pesquisa e de posicionamentos teóricos. Não é incomum encontrarmos julgamentos do tipo: "o paradigma crítico-dialético é o melhor, por ser o "mais crítico" ou "o paradigma empírico-analítico é o único que presta, por ser o mais 'sério' e 'realmente científico"”. Tal tipo de posicionamento "medieval" (no sentido de "inquisitório") deve ser a todo custo evitado. Ao aluno devem ser apresentadas as diversas possibilidades de escolha, sem julgamento de valores e/ou restrições apriorísticas.

Algumas preocupações expressas por Alexandre Fernandez $\mathrm{Vaz}^{18}$ parecem bastante válidas para pensarmos essa questão da restrição de oferecimento de possibilidades aos alunos. O autor critica a utilização de certos jargões que expressam um suposto caráter crítico, em muitos casos equivocadamente considerados suficientes para justificar a validade e a importância da investigação.

Enfim, não podemos aceitar que somente o caráter empíricoanalítico, ligando a pesquisa às ciências exatas ou da natureza, legitime o estudo. Mas também devemos estar atentos à crítica de Vaz:

Uma produção acaba sendo válida se ela contém o caráter 'crítico' e se cita alguns autores notadamente 'progressistas' (mesmo que a fonte original não tenha sido consultada, e mal se saiba de quem se está falando ou o que de fato querem dizer os conceitos utilizados)". ${ }^{19}$

Importante observar que, mais do que simplesmente de forma aparente oferecer, devemos procurar ao máximo dar estímulos distribuídos, relacionados às diversas possibilidades de pesquisa. E isso está ligado ao próprio enfoque predominante na formação profissional. No caso da UFRJ, por exemplo, onde existe uma clara valorização do conhecimento técnico e biomédico, não surpreende que apareçam poucos alunos interessados em estudos ligados às ciências sociais e humanas.

Com certeza isso nos trás algumas reflexões. Aliada à competência e disponibilidade dos professores ligados às áreas biomédicas, pode estar existindo um desequilíbrio na oferta de estímulos ligados às áreas de humanas e sociais. Ao mesmo tempo, 
pode existir uma certa incapacidade dos professores das áreas menos procuradas para que os alunos reconheçam e despertem curiosidades ligadas a seus assuntos. De outra forma, seria mais louvável se a formação profissional induzisse para um equilíbrio e não privilegiasse uma determinada área. Não parece haver uma explicação única e linear, mas um todo complexo.

Observe-se que não estou a afirmar que é ruim muitos alunos desenvolverem trabalhos ligados à natação ou à fisiologia, mas creio que devemos ampliar os estímulos para outras áreas. E, se isso é responsabilidade dos professores das disciplinas ligadas às ciências humanas e sociais, também o é do contexto geral da formação profissional.

Bem, essas são as reflexões desenvolvidas nesses dois anos de experiência. Por certo elas possuem grandes limites por serem diretamente referentes a minha vivência na EEFD/UFRJ. Contudo creio que elas podem contribuir com outros colegas, de outras instituições, para que possamos formar melhor nossos alunos, reorientando os sentidos da pesquisa no âmbito de nossos cursos de graduação, o que com certeza pode trazer reflexos futuros em nossa área de conhecimento, inclusive no âmbito dos programas de pós-graduação.

\begin{abstract}
The purpose of this study is to discuss the educational foundation related to the demand of a research paper at the end of the course, in the scope of the Escola de Educação Física e Desportos da Universidade Federal do Rio de Janeiro (EEFD/UFRJ) - the School of Physical Education and Sports of the Federal University of Rio de Janeiro. This article is inserted in an attempt to catalogue and publish the abstracts of the monographs presented for Physical Education bachelor's degree at EEFD/UFRJ. The revision, reovery, classification and analyzes of the monographs presented in this article is not intended to discuss the theoretical and methodological position of these studies. It is aimed at discussing the conception and operational problems which arese around the demand to present a monograph. From the experience at EEFD/UFRJ, such problems were traced down in order to open the discussions and contributions among peers and other institutions that wish to think and rethink the importance of monographs which, more than an official demand, should be understood as a portrait of the way researches are measured in the formation of professionals.

KEYWORDS: Research-Professional Formation-Monographs.
\end{abstract}




\begin{abstract}
NOTAS
${ }^{1}$ Maiores informações sobre a Escola podem ser obtidas no estudo: SILVA, Dirce Maria Corrêa da. Escola de Educação Física do Espírito Santo: suas histórias, seus caminhos (1931-1961). In: FERREIRA NETO, Amarílio. Pesquisa histórica na Educação Física - 2. Vitória: CEFD/UFES, 1997. p.157-168. Os interessados nos títulos apresentados pelos alunos do Espírito Santo, no momento inicial de funcionamento da Escola, podem consultar em: MARINHO, Inezil Penna. Contribuição para a história da Educação Física no Brasil. Rio de Janeiro: Imprensa Nacional, 1943.

${ }^{2}$ Maiores informações sobre a exigência de monografias para conclusão do curso, em diferentes contextos, podem ser obtidas em: PESSOA FILHO, Dalton, PELLEGRINI, Ana Maria. Evolução, tendências e contribuição do trabalho de formatura nos cursos de Educação Física da UNESP/RC. Motriz, Rio Claro, v.3, n.1, p.1-10, junho 1997; PINTO, Ricardo Figueiredo, MARCO, Ademir de. A iniciação científica, em Educação Física, não vai bem no Brasil! Corpoconsciência, Santo André, n.4, p. 33-42, 1999; LAZAROTTI FILHO, Ari, SOUSA, Iracema Soares. Direções teóricometodológicas do curso de Educação Física da UFSC: identificando contradições. Motrivivência, Florianópolis, ano XI, n.13, p.119136, novembro/1999.

${ }^{3}$ Maiores informações podem ser obtidas em: ALVES, Neil Christian Borges. Estrutura curricular dos cursos de Educação Física da EEFD/UFRJ. Rio de Janeiro, 1999. Monografia (Bacharelado em Educação Física). - Universidade Federal do Rio de Janeiro.

${ }^{4}$ UFRJ/EEFD. Reformulação do curso de Educação Física. Rio de Janeiro, 1991. Mimeografado. UFRJ/EEFD. Proposta curricular do curso de bacharelado em Educação Física. Rio de Janeiro, 1994. Mimeografado.

${ }^{5} \mathrm{Na}$ verdade, não estou falando de uma disciplina, mas sim de um "Requisito Curricular Suplementar (RCS)". Logo, de um espaço com características diferenciadas às de uma disciplina.

${ }^{6}$ MELO, Victor Andrade de. Monografias do bacharelado: resumos. Rio de Janeiro: UFRJ, 2000. Mimeografado. Há trabalho que pode ser conferido na página da EEFD/UFRJ (http://
\end{abstract}


www.eefd.ufrj.br) e que só foi possível graças ao empenho e colaboração de Mônica Carvalho e de toda equipe do Laboratório de Informática da Escola, a quem agradeço.

7 A Escola recebe, por ano, aproximadamente 400 alunos para seus 3 cursos, o que significa mais de 1.000 alunos circulantes para cerca de 80 professores divididos em 6 departamentos.

${ }^{8}$ DEMO, Pedro. Universidade e pesquisa: agonia de um antimodelo. Motrivivência, Florianópolis, ano V, n. 5/6/7, p.21, dez. 1999.

${ }^{9}$ Ibidem, p.24.

${ }_{10}$ Atualmente somente cinco alunos da Escola possuem bolsas PIBIC/CNPq.

${ }^{11}$ DEMO,op.cit.

${ }^{12}$ Idem, ibidem.

${ }^{13}$ Uma discussão interessante sobre as normas da ABNT pode ser encontrada em: LUZ, Iraci Borges Pereira, GONÇALVES, Aguinaldo, BORGES, Vera Lucia. Referências bibliográficas em ciências do esporte: conhecendo e aplicando recomendações técnicas. Movimento, Porto Alegre, ano 3, n.4, p.6-17, 1996/1.

${ }^{14}$ DEMO, op.cit. p. 18.

${ }^{15} \mathrm{O}$ orientador deve conceder até dez pontos para a monografia e cinco pontos para o processo. Um convidado concederá até dez pontos para o "produto" final. O professor de Monografia concederá até cinco pontos pelo processo. A nota final é a média das três notas.

${ }^{16}$ DEMO, op.cit., p. 19.

${ }^{17}$ Idem, Ibidem.

${ }^{18}$ VAZ, Alexandre Fernandez. A pesquisa como prática pedagógica - uma resposta à pergunta "Pesquisa em Educação Física: para quê e para quem?". Motrivivência, Florianópolis, ano V, n. 5/6/7, p.6062, dezembro/1994.

${ }^{19}$ Ibidem, p.61.

\section{REFERÊNCIAS}

ALVES, Neil Christian Borges. Estrutura curricular dos cursos de Educação Física da EEFD/UFRJ. Rio de Janeiro, 1999. Monografia (Bacharelado em Educação Física) - Universidade Federal do Rio de Janeiro.

44 Melo,V. A. de - Monografias de fim de curso... 
DEMO, Pedro. Universidade e pesquisa: agonia de um antimodelo. Motrivivência, Florianópolis, ano V, n. 5/6/7, p. 17-33, dez. 1994.

LAZAROTTI FILHO, Ari; SOUSA, Iracema Soares. Direções teórico-metodológicas do curso de Educação Física da UFSC: identificando contradições. Motrivivência, Florianópolis, ano XI, n. 13, p. 119-136, nov. 1999.

LUZ, Iraci Borges Pereira; GONÇALVES, Aguinaldo; BORGES, Vera Lucia. Referências bibliográficas em ciências do esporte: conhecendo e aplicando recomendações técnicas. Movimento, Porto Alegre, ano 3, n. 4, p. 6-17, 1996/1.

MARINHO, Inezil Penna. Contribuição para a História da Educação Física no Brasil. Rio de Janeiro: Imprensa Nacional, 1943.

MELO, Victor Andrade de. Monografias do bacharelado: resumos. Rio de Janeiro: UFRJ, 2000. Mimeografado.

PESSOA FILHO, Dalton; PELLEGRINI, Ana Maria. Evolução, tendências e contribuição do trabalho de formatura nos cursos de Educação Física da UNESP/RC. Motriz, Rio Claro, v. 3, n. 1, p. 1-10, jun. 1997;

PINTO, Ricardo Figueiredo; MARCO, Ademir de. A iniciação científica, em Educação Física, não vai bem no Brasil! Corpoconsciência, Santo André, n. 4, p. 33-42, 1999.

SILVA, Dirce Maria Corrêa da. Escola de Educação Física do Espírito Santo: suas histórias, seus caminhos (1931-1961). In: FERREIRA NETO, Amarílio. Pesquisa histórica na Educação Física - 2. Vitória: CEFD/UFES, 1997. p. 157-168.

UFRJ/EEFD. Reformulação do curso de Educação Física. Rio de Janeiro, 1991. Mimeografado.

UFRJ/EEFD. Proposta curricular do curso de bacharelado em Educação Física. Rio de Janeiro, 1994. Mimeografado.

VAZ, Alexandre Fernandez. A pesquisa como prática pedagógica uma resposta à pergunta "Pesquisa em Educação Física: para quê e para quem?". Motrivivência, Florianópolis, ano V, n. 5/6/7, p. 6062, dez. 1994. 